\title{
APLIKASI KOMPUTER UNTUK VISUALISASI POLA SEBARAN KONSENTRASI GAS DARI SUMBER TITIK INSTAN DALAM FLUIDA DIAM DAN MEDIUM ANISOTROP
}

\author{
SUPRIYONO \\ Sekolah Tinggi Teknologi Nuklir - Badan Tenaga Nuklir Nasional \\ Jl. Babarsari Kotak Pos 6101 YKBB Yogyakarta 55281 \\ Telp : (0274) 480485, 489716 ; Fax : (0274) 489715 \\ E-mail : masprie_sttn@yahoo.com
}

\begin{abstract}
Abstrak
APLIKASI KOMPUTER UNTUK VISUALISASI POLA SEBARAN KONSENTRASI GAS DARI SUMBER TITIK INSTAN DALAM FLUIDA DIAM DAN MEDIUM ANISOTROP. Telah dibuat suatu aplikasi komputer untuk menvisualkan suatu sebaran konsentrasi gas akibat terjadinya suatu kebocoran gas, misalnya pada pipa pemboran gas bumi. Aplikasi ini dibuat untuk dijadikan salah satu komponen dalam sistem pemantauan lingkungan pada daerah industri atau daerah pertambangan, yaitu supaya tersedia suatu informasi awal tentang kemungkinan tercemarnya suatu daerah akibat adanya kebocoran pipa gas. Model yang digunakan dalam penelitian ini adalah model difusi tak tunak dari sumber titik instan dalam fluida diam dan model difusi dari sumber titik instant di dalam medium anisotrop dan penggambaran konsentrasi gas yang berasal dari sumber kebocoran pipa adalah kurva distribusi Gauss. Aplikasi komputer ini berbentuk simulasi dengan disediakan berbagai macam fasilitas input data dan hasilnya berupa angka-angka, grafik 3-dimensi maupun 2 dimensi dan pilihan bentuk grafik. Untuk membangun aplikasi ini digunakan perangkat lunak Matlab 6.1. Dengan melakukan Simulasi terhadap berbagai macam variabel masukan, maka aplikasi komputer ini akan menghasilkan sejumlah prediksi konsentrasi gas dalam bentuk pola 2-dimensi, 3dimensi, dan kontur.
\end{abstract}

Kata Kunci : Aplikasi komputer, Pola sebaran, Konsentrasi Gas, Model difusi, 2dimensi, 3-dimensi, Matlab

\begin{abstract}
A COMPUTER APPLICATION FOR VISUALIZATION OF THE GAS CONCENTRATION PATTERNS FROM INSTANT POINT SOURCE IN FLUID STATIC AND ANISOTROPY MEDIUM. The computer application for visualization of the gas concentration patterns the effect from gas leakage for example the pipe leakage of the fuel gas drilling, has been done. The application developed to assist one of the components in environmental control system in
\end{abstract}


industrial area or mining area, I.e. in order to forecasting of an area contaminated the effect from pipe leakage available. The model used of unsteady state diffusion model from instant point source in fluid static and diffusion model from instant point source in anisotropy medium. The gas concentration illustrate to come from pipe leakage source is a Gauss distribution curve. The model of this computer application is simulation model with data input facilities and the simulation result is three and two dimension graph. For developed of the computer program used Matlab 6.1. By varying in inputs, the computer application produces numerous concentration gas predictions as 2-dimension, 3-dimension and contour patterns.

Keywords : Computer application, patterns, Gas concentration, Diffusion model, 2Dimension, 3-Dimension, Matlab

\section{PENDAHULUAN}

Pada umumnya pencemaran udara berupa konsentrasi gas terjadi di lapisan bawah atmosfer, yaitu troposfer dan stratosfer. Hal ini disebabkan oleh sebagian besar massa atmosfer berada di kedua lapisan tersebut. Selain itu, biasanya penyebaran gas terdapat di permukaan bumi ${ }^{[1]}$. Sebaran gas akibat kebocoran pipa gas dapat diketahui dengan pengamatan langsung di tempat terjadinya kebocoran, yaitu dengan mengambil sampel berupa tanah dan tumbuhan lalu dianalisis yang membutuhkan biaya tinggi. Oleh karena itu perlu suatu upaya penyelamatan lingkungan berupa penyediaan informasi awal tentang kemungkinan tercemarnya suatu daerah akibat adanya kebocoran pipa gas. Dengan tersedianya informasi ini, maka akan banyak membantu dalam antisipasi terhadap dampak pencemaran tersebut. Salah satu bentuk informasi awal yang dapat dibuat adalah berupa aplikasi komputer untuk visualisasi pola sebaran konsentrasi gas akibat terjadinya kebocoran gas.

Dalam membangun aplikasi komputer ini dasar membangun model matematikanya adalah teori difusi yang termasuk dalam teori transport. Adapun penyelesaian eksak Persamaan difusi yang digunakan adalah :

1. Difusi tak tunak dari sumber titik instant dalam fluida diam.

2. Difusi dari sumber titik instant di dalam medium anisotrop.

Setelah dihasilkan model matematik maka dilanjutkan dengan menyusun analisis kebutuhan berupa kebutuhan input, proses, output serta perangkat lunak dan perangkat kerasnya. Dalam hal ini perangkat lunak yang digunakan adalah Matlab 6.1 dengan alasan bahwa Matlab adalah perangkat lunak yang memuat subroutine penyelesaian matematika dan metode numerik yang disertai dengan grafik yang lengkap dan dapat dijalankan sebagai bahasa pemrograman yang berorientasi obyek serta mempunyai fasilitas GUI (Graphical User Interfase) yang cukup memadai. 
Hasil aplikasi komputer ini diharapkan dapat menjadi alat bantu pemantauan lingkungan dari suatu fasilitas pabrik maupun pemboran gas bumi, misalnya adalah dengan menjalankan aplikasi ini, maka akan dapat diketahui sebaran gas Hidrogen Sulfida pada kebocoran pipa pada suatu pemboran gas bumi. Aplikasi ini juga dapat digunakan sebagai alat bantu ajar untuk pelajaran-pelajaran yang berhubungan dengan teknik lingkungan, maupun pada diklat-diklat analisis lingkungan. Aplikasi ini dapat juga digunakan sebagai alat bantu ajar pembuatan simulasi.

\section{DASAR TEORI}

Penyebaran polutan berupa gas ke lingkungan terjadi menurut gabungan beberapa proses transport, yaitu difusi molekular (Fickian diffusion process) dan proses hanyutan oleh aliran udara (advection process). Secara umum proses transport gas di udara dapat dirumuskan dengan rumus $^{[2]}$ :

$$
D_{x} \frac{\partial^{2} C}{\partial x^{2}}=\frac{\partial C}{\partial t}
$$

dengan :

$C=$ Konsentrasi polutan.

$D_{x}=$ Koefisien difusi efektif.

$x=$ variabel jarak dan $t$ adalah waktu.

Pada $x=\infty$, yaitu pada jarak yang cukup jauh dari sumber, $C=0$ sebagai syarat batas dan dengan transformasi Laplace, Persamaan (1) sebagai Persamaan difusi yang diformulasikan dalam koordinat bola dapat diselesaikan menjadi Persamaan berbentuk :

$$
C=\frac{Q}{(4 \pi D t)^{2 / 3}} \exp \left(-\frac{r^{2}}{4 D t}\right)
$$

dengan :

$$
r^{2}=x^{2}+y^{2}+z^{2} \quad \quad \quad \text { dan } Q=4 \Pi \int_{00}^{\infty} C(r, t) r^{2} d r
$$

Menurut $^{[2]}$, bentuk distribusi Persamaan 2 adalah distribusi normal biasa, sehingga konsentrasinya selalu maksimum pada $r=0$. Lebar dari kurvanya 
membesar dengan waktu, sedang posisi $r_{1 / 2}$ yaitu jarak konsentrasi menjadi setengah dari harga titik asal diberikan oleh Persamaan :

$$
r_{1 / 2}=2(\ln 2)^{1 / 2}(D t)^{1 / 2}
$$

Selain itu, dapat juga dihitung sebaran bahan dengan difusi molekuler sebagai pergeseran radial kwadrat rata-rata $\sigma_{r}{ }^{2}$ dengan menjumlahkan ke seluruh ruang hasil kali konsentrasi di setiap elemen volume dengan kwadrat jarak ke titik asal. Dengan membaginya dengan massa total yang dilepas, diperoleh Persamaan berbentuk :

$$
r_{\sigma}{ }^{2}=\frac{1}{Q} \sum_{i} C\left(r_{i}\right) r_{i}^{2} d V_{i}=\frac{4 \pi}{Q} \int_{0}^{\infty} C r^{4} d r=6 D t
$$

Pergeseran kwadrat rata-ratanya sering dinyatakan sebagai jumlah dari ketiga komponen arahnya $\mathrm{x}, \mathrm{y}$, dan $\mathrm{z}$, yaitu : $\sigma_{r}{ }^{2}=\sigma_{x}{ }^{2}+\sigma_{y}{ }^{2}+\sigma_{z}{ }^{2}$. Karena $\sigma^{2}=2 D t$, maka Persamaan (2) menjadi :

$$
C=\frac{Q}{(2 \pi)^{2 / 3} \sigma^{3}} \exp \left(-\frac{r^{2}}{2 \sigma^{2}}\right)
$$

Persamaan 5 merupakan penyelesaian umum dari Persamaan difusi tak tunak dari sumber titik instant dalam fluida diam.

Penyelesaian umum persamaan difusi dari sumber titik instant di dalam medium anisotrop, diawali dari bentuk umum Persamaan difusi :

$$
\frac{\partial C}{\partial t}=\frac{\partial}{\partial x}\left(D x \frac{\partial C}{\partial x}\right)+\frac{\partial}{\partial y}\left(D y \frac{\partial C}{\partial x}\right)+\frac{\partial}{\partial z}\left(D z \frac{\partial C}{\partial z}\right)
$$

dengan langkah-langkah penyelesaian seperti pada penyelesaian Persamaan difusi tak tunak dari sumber titik instant dalam fluida diam di atas, maka dihasilkan penyelesaian umum untuk Persamaan difusi dari sumber titik instant di dalam medium anisotrop sebagai berikut :

$$
\begin{aligned}
& C=\frac{Q}{(2 \pi)^{2 / 3} \sigma_{x} \sigma_{x} \sigma_{x}} \times \\
& \exp \left(-\frac{x^{2}}{2 \sigma_{x}{ }^{2}}-\frac{y^{2}}{2 \sigma_{y}{ }^{2}}-\frac{z^{2}}{2 \sigma_{z}{ }^{2}}\right)
\end{aligned}
$$


Persamaan 5 dan 7 itulah yang menjadi dasar Pembuatan algoritma untuk aplikasi ini.

Pada Persamaan 7 untuk perhitungan $\sigma_{y}$ dan $\sigma_{z}$ harus disesuaikan dengan kondisi di lapangan, yaitu harus disesuaikan dengan kecepatan angin dan kestabilan atmosfer. Menurut ${ }^{[3]}$ dan $^{[4]}$, tetapan horizontal dinyatakan dengan:

$$
\sigma_{y}=a x^{0.894}
$$

dan tetapan dispersi vertikal dinyatakan dengan

$$
\sigma_{z}=c x^{d}+f
$$

Nilai $a, \mathrm{c}, d$, dan $f$ tergantung pada kestabilan atmosfer yang angka-angkanya sesuai dengan Tabel 1.

Tabel 1. Nilai Tetapan a, c, d dan f untuk Persamaan 8 dan $9^{[4]}$

\begin{tabular}{cccccccc}
\hline & & \multicolumn{3}{c}{$\mathrm{x} \leq 1 \mathrm{~km}$} & \multicolumn{3}{c}{$\mathrm{x} \geq 1 \mathrm{~km}$} \\
\cline { 3 - 8 } Kestabilan & $a$ & $c$ & $d$ & $f$ & $c$ & $d$ & $f$ \\
\hline A & 213 & 440,8 & 1,941 & 9,27 & 459,7 & 2,094 & $-9,6$ \\
B & 156 & 106,6 & 1,149 & 3,3 & 108,2 & 1,098 & 2,0 \\
C & 104 & 61,0 & 0,911 & 0 & 61,0 & 0,911 & 0 \\
D & 68 & 33,2 & 0,725 & $-1,7$ & 44,5 & 0,516 & $-13,0$ \\
E & 50,5 & 22,8 & 0,678 & $-1,3$ & 55,4 & 0,305 & $-34,0$ \\
F & 34 & 14,35 & 0,740 & $-0,35$ & 62,6 & 0,180 & $-48,6$ \\
\hline
\end{tabular}

Untuk menentukan klasifikasi A, B, C, D, E dan F pada Tabel 1. di atas, maka menurut ${ }^{[5]}$ perhitungannya bergantung pada kecepatan angin permukaan, pancaran sinar matahari dan derajat awan. Adapun hasil perhitungannya dapat disusun dalam Tabel 2.

Tabel 2. Nilai tetapan a, b, c, d, e dan f untuk Tabel $1^{[4]}$

\begin{tabular}{cccccc}
\hline \multirow{2}{*}{$\begin{array}{c}\text { Kecepatan angin permukaan } \\
(\mathrm{m} / \text { det })\end{array}$} & \multicolumn{3}{c}{ Pancaran Sinar Matahari } & \multicolumn{3}{c}{ Pancaran Sinar Matahari } \\
\cline { 2 - 7 } & \multicolumn{3}{c}{ Siang hari } & \multicolumn{3}{c}{ Malam hari } \\
\cline { 2 - 7 } & Kuat & Sedang & Lemah & Banyak & Bersih \\
\hline$<2$ & A & A - B & B & E & F \\
$2-3$ & A - B & B & C & E & F \\
$3-5$ & B & B - C & C & D & E \\
$5-6$ & C & C - D & D & D & D \\
$>6$ & C & D & D & D & D \\
\hline
\end{tabular}




\section{BAHAN DAN METODE}

Untuk membangun suatu aplikasi komputer, dibutuhkan suatu model, yang mewakili suatu obyek atau aktifitas. Salah satu model tersebut adalah model matematika yang telah disusun di dalam dasar teori. Dalam hal ini model matematika yang digunakan sebagai bahan Pembuatan aplikasi adalah Persamaan 5 dan 7.

Setelah Persamaan model siap, maka langkah berikutnya adalah menyiapkan perangkat keras dan perangkat lunak, guna pembuatan aplikasi. Untuk membangun aplikasi komputer ini sebagai bahan penelitian digunakan perangkat keras dan perangkat lunak sebagai berikut :

\section{Perangkat Keras Berupa Komputer dengan Spesifikasi :}

Sistem ini dibangun dengan perangkat keras Intel(R) Pentium(M) $1500 \mathrm{MHz}$, Memori 512 MB dan Hard disk dengan kapasitas 80GB.

\section{Perangkat Lunak :}

Perangkat lunak yang diperlukan adalah sebagai berikut.

1. Microsoft Windows XP

2. Bahasa Pemrograman Matlab 6.1.

Dalam Pembuatan perangkat lunak untuk aplikasi komputer ini digunakan prinsip-prinsip rekayasa perangkat lunak, yaitu dengan digunakannya metode Water fall (air terjun ${ }^{[6]}$. Adapun tahapan-tahapan dalam model air terjun ini adalah :

3. Analisis dan rekayasa sistem.

Pada tahapan ini yang dilakukan meliputi aspek-aspek yang berkaitan dengan perencanaan dan pengendalian masalah, yaitu dengan adanya persoalan perhitungan konsentrasi untuk Persamaan difusi tak tunak dari sumber titik instant dalam fluida diam dan Persamaan difusi dari sumber titik instant di dalam medium anisotrop.

4. Analisis persyaratan.

Agar aplikasi komputer dapat bersifat user-friendly, maka system harus dibuat semudah mungkin penggunaannya. Dengan alasaan inilah dalam penelitian ini digunakan perangkat lunak Matlab 6.1. Sebagai perangkat lunak yang mendukung pemrograman berorientasi obyek. Matlab 6.1 juga menyediakan kemampuan numerik yang handal dan penyediaan fasilitas grafik yang memadai.

5. Perancangan.

Untuk membuat aplikasi komputer ini, sebelum dibangun program dibuat dulu perancangan antar muka. Dalam perancangan ini dibuat pula analisis kebutuhan, yaitu kebutuhan input, proses sebagai rancangan program dan output. Dalam kebutuhan proses tersebut algoritma pemrogramannya adalah sebagai berikut, berdasarkan algoritma perhitungan konsentrasi 
sebagai kebutuhan proses ditampilkan pada tahapan perancangan ini. Kedua algoritma tersebut sebagai berikut:

a. Algoritma Pemrograman untuk model difusi dari sumber titik instan dalam fluida diam (berdasarkan Persamaan 5).

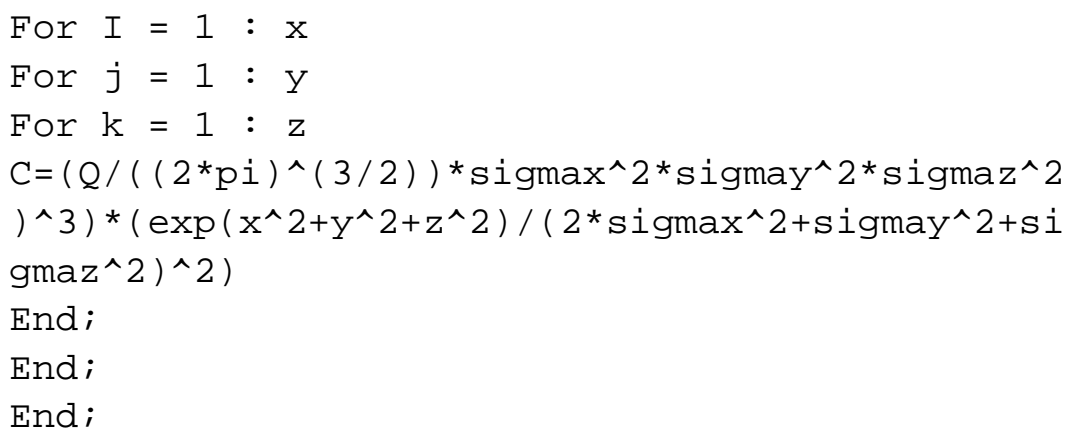

b. Algoritma Pemrograman untuk model difusi dalam medium anisotropy (berdasarkan Persamaan 7).

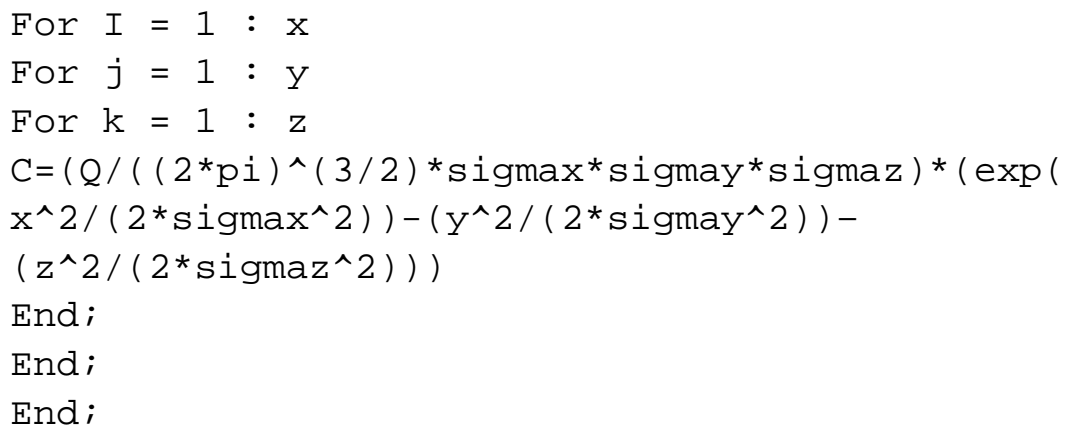

6. Penulisan program.

Menterjemahkan rancangan antar muka dan rancangan program kedalam bahasa pemrograman Matlab 6.1.

7. Pengujian.

Setelah dibangun program, hasil outputnya diuji dengan penyelesaian secara manual untuk kasus yang sederhana serta dianalisis dengan kondisi yang nyata, misalkan diujikan pada kasus kebocoran gas di pipa pemboran gas bumi.

8. Pemeliharaan.

Agar sistem ini dapat selalu digunakan, maka sistem harus disimpan dalam bentuk back up elektronis (Hard disk, CD maupun disket) dan back up dalam listing program. 


\section{HASIL DAN PEMBAHASAN}

Setelah sistem dapat terbangun, maka langkah berikutnya adalah menjalankan program, yaitu menguji apakah program dapat berjalan dengan baik atau tidak. Untuk itu program utama dengan nama file utama.M ini dijalankan pada Matlab Command Window's. Hasilnya adalah tampilan awal yang mempunyai fasilitas berupa pilihan-pilihan menu Difusi Fluida Diam dan Difusi Anisotrop.

Pada tampilan awal tersebut, mula-mula pada pada daerah grafik masih berupa daerah kosong. Dengan memasukkan angka-angka percobaan seperti yang tertera pada sebelah kanan atas berupa parameter-parameter jangkauan laju emisi polutan, jarak penyebaran polutan dan keadaan atmosfer, maka dengan memilih menu eksekusi berupa pilihan pada menu Pola Sebaran akan muncul pilihan untuk melakukan eksekusi, yaitu pilihan untuk menampilkan Grafik 3-dimensi, Grafik 3-dimensi beserta angka tampilan dan Grafik 2dimensi berupa grafik kontur. Dalam aplikasi ini juga dilengkapi dengan fasilitas untuk kembali ke halaman cover atau keluar ke Window's. Selain itu juga dapat langsung menuju ke menu. Difusi Anisotrop jika aplikasi berada dalam daerah Fluida Diam dan sebaliknya.

Jika pada saat tampilan cover memilih menu Difusi Fluida Diam dan diisi dengan input-input daerah jangkauan pengamatan $20 \mathrm{~km}$ dan simulasi ini diasumsikan bahwa laju emisi polutan adalah $458 \mathrm{~kg} / \mathrm{jam}$, jangkauan penyebaran polutan 7,7 km ke arah x, 4,5 km kearah y dan 2,5 km ke arah z serta kestabilan atmosfer dimisalkan dalam kondisi A maka akan muncul tampilan seperti pada Gambar 1.

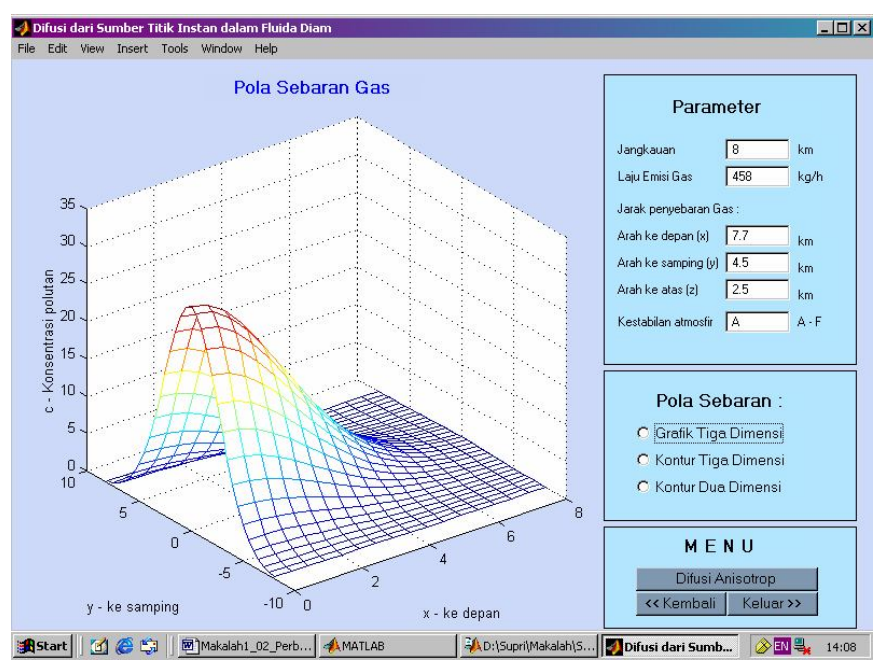

Gambar 1. Tampilan Input untuk Difusi Fluida Diam dan Grafiknya 
Hasilnya merupakan suatu nilai konsentrasi gas berbentuk grafik 3-dimensi dan gas menyebar mengikuti distribusi Gauss. Sehingga sebaran gas yang terbesar terjadi sepanjang pusat sebaran. Gambar 1 menunjukkan bahwa konsentrasi maksimal berada di dalam radius $1 \mathrm{~km}$, yaitu sekitar $18 \mathrm{~kg} / \mathrm{km} 3$ dan setelah $6 \mathrm{~km}$ dari pusat sebaran, konsentrasi gas berangsur-angsur mendekati nol. Dalam pemasukan data ini, kondisi atmosfer diasumsikan dalam kestabilan A, yang berarti kondisi atmosfir sangat tidak stabil, sedangkan untuk kondisi yang stabil kestabilannya bernilai F. Adapun untuk kestabilan atmosfer yang netral dipilih kondisi D. Dalam aplikasi ini disediakan pula fasilitas Gambar 2-dimensi yang berbentuk kontur (sudut pandang dari atas). Untuk menampilkan kontur sudut pandang dari atas, dapat memilih menu Kontur Dua Dimensi dan hasilnya adalah Gambar 2.

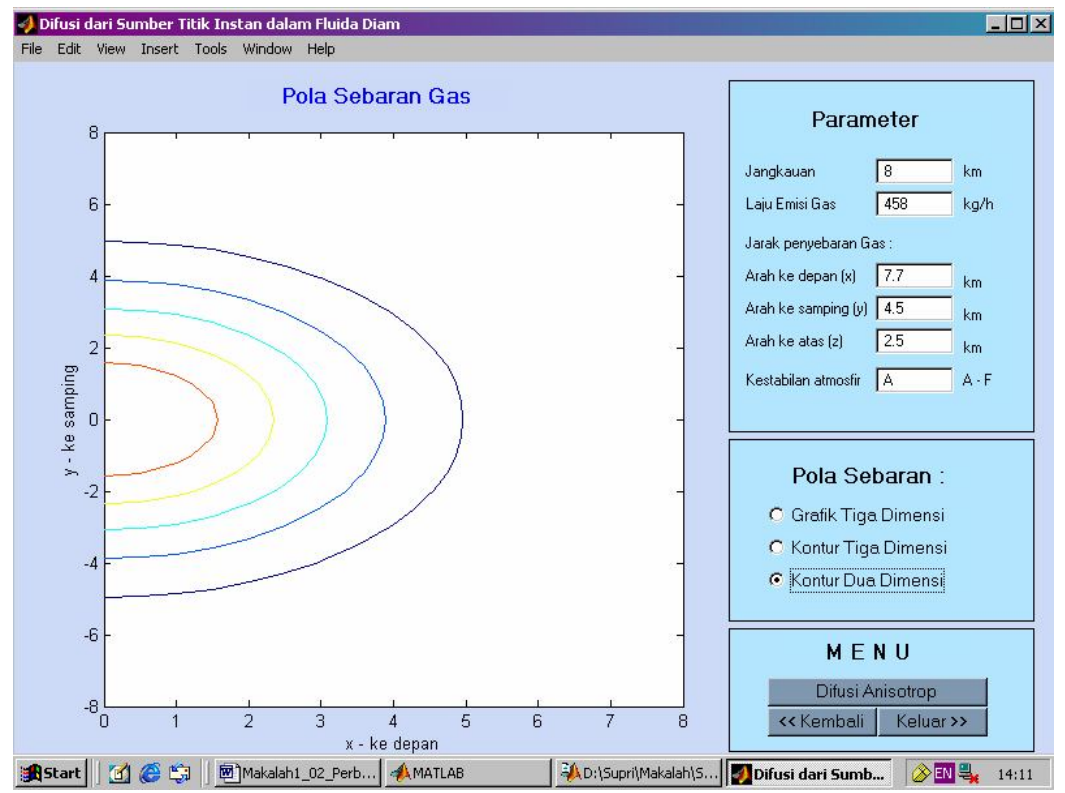

Gambar 2. Tampilan Grafik 2-Dimensi untuk Difusi Fluida Diam

Grafik kontur pada Gambar 2. di atas memperlihatkan sejumlah tanda ketebalan warna, bahwa warna semakin tua menggambarkan kadar polutan semakin tinggi. Gambar 2 dan Gambar 3 di atas adalah hasil untuk model difusi dari sumber titik instan dalam fluida diam. Gambar 2 mempertegas keterangan Gambar 1 yaitu bahwa pada daerah radius antara $1-2 \mathrm{~km}$ terjadi penyebaran yang maksimum dan pada radius $5-6 \mathrm{~km}$ konsentrasi sebaran berangsur-angsur mendekati nol. 
Perhitungan pada model difusi dari sumber titik instan dalam medium anisotrop dilakukan dengan cara memilih menu Difusi Anisotrop dengan memasukkan parameter-parameter sebagai berikut.

1. Jenis gas : H2S (Hidrogen Sulfida)

2. Laju Emisi $\quad: 458 \mathrm{~km} / \mathrm{jam}$

3. Jarak Sebaran
a. $\operatorname{Ke}$ depan $(\mathrm{x}) \quad: 0,9 \mathrm{~km}$
b. Ke samping (y) : $0,75 \mathrm{~km}$
c. Ke atas (z): $0,5 \mathrm{~km}$
4. Kestabilan Atmosfer : A (Sangat tidak stabil)
5. Jangkauan Pengamatan : $20 \mathrm{~km}$

Hasil eksekusi berupa pola sebaran gas berdasarkan model difusi anisotrop pada aplikasi ini yang ditampilkan seperti pada Gambar 3. Kasus di atas adalah kasus pencemaran yang terjadi pada kebocoran pipa gas bumi di Dieng pada tahun 1997.

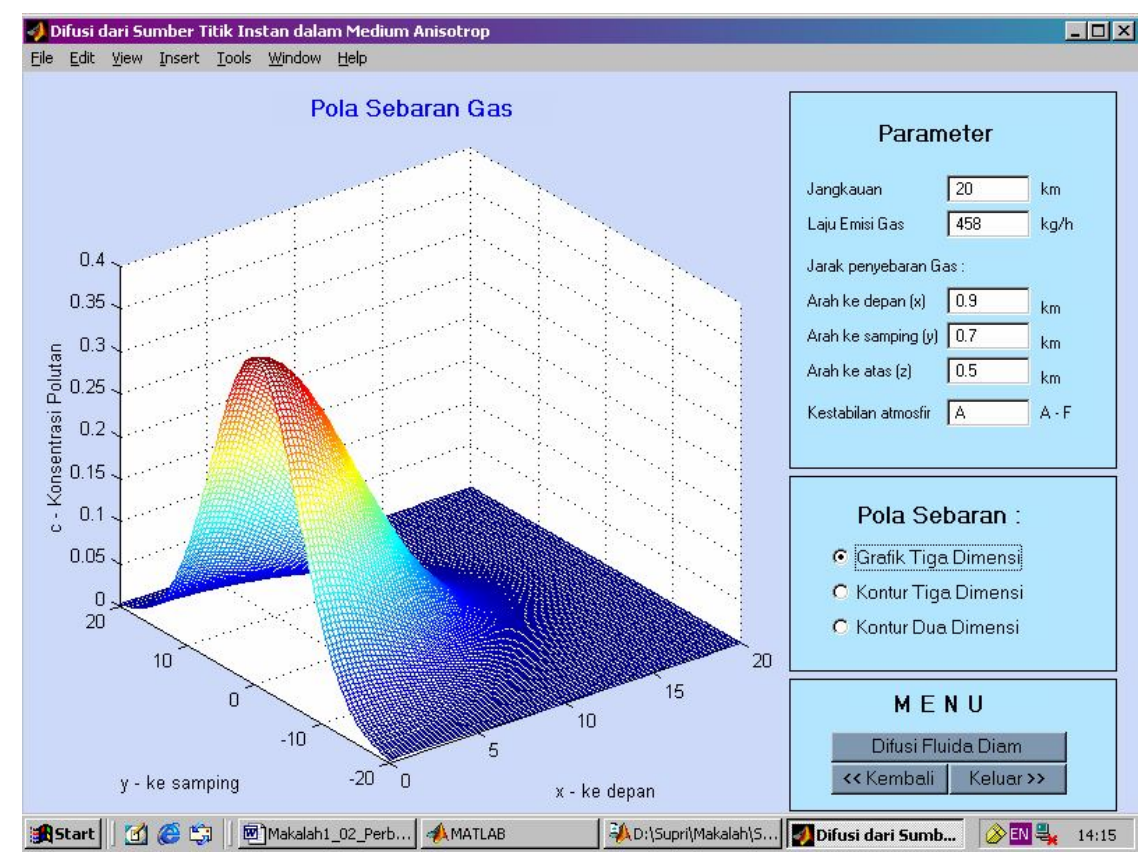

Gambar 3. Tampilan Input untuk Difusi Anisotrop dan Grafiknya 


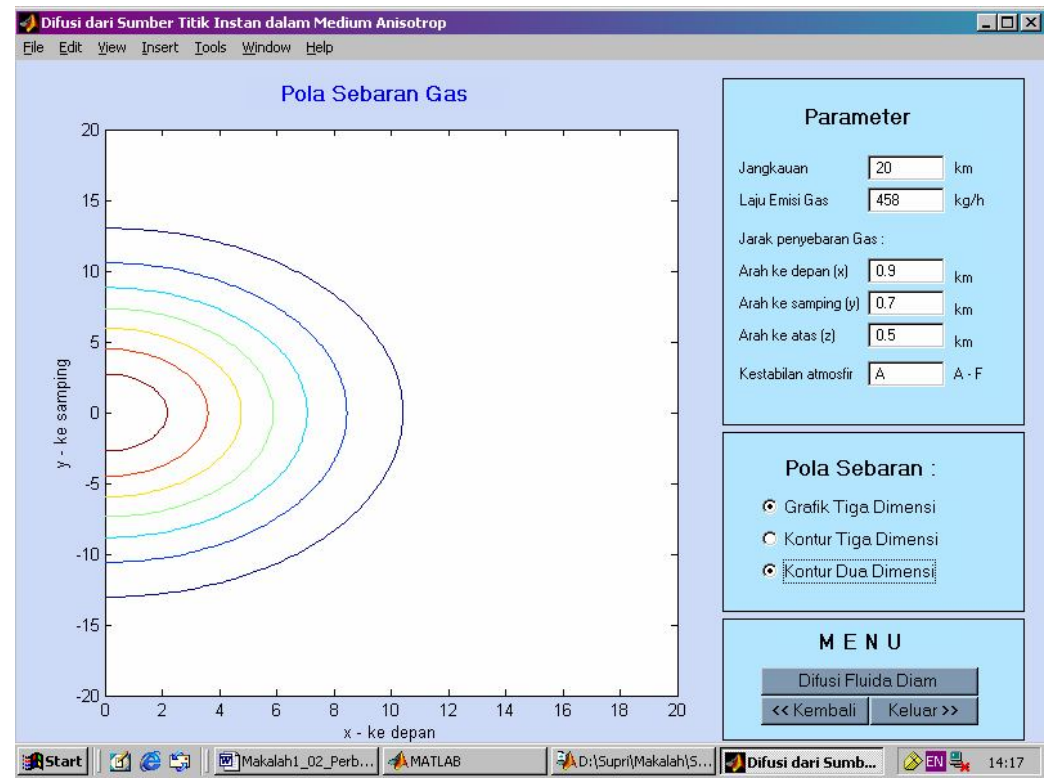

Gambar 4. Tampilan Kontur untuk Difusi Anisotrop

Berdasarkan Gambar 3 diketahui bahwa konsentrasi polutan yang tertinggi terjadi di sekitar pusat pencemaran sampai dengan $0,5 \mathrm{~km}$. Artinya pencemaran yang terjadi pada tahun 1997 hanya terpusat pada daerah kebocoran pipa.

Pola sebaran gas dapat pula digambarkan dalam bentuk kontur, sehingga dengan melihat konturnya akan terlihat daerah-daerah mana saja yang akan terkena sebaran gas. Pola sebaran dalam bentuk kontur, ditampilkan pada Gambar 4 di atas. Pola tersebut menunjukkan adanya empat buah segmen degradasi konsentrasi gas. Artinya segmen terluar menggambarkan daerah jatuhan dengan konsentrasi gas terendah 0,054519 $\mathrm{kg} / \mathrm{km} 3$, segmen berikutnya mengandung konsentrasi gas lebih tinggi dan seterusnya sampai kadar tertinggi pada segmen terdalam, yaitu sebesar $0,54518 \mathrm{~kg} / \mathrm{km} 3$ dan polutan tersebar sejauh $+10 \mathrm{~km}$. Jika sebaran gas tersebut merupakan gas pencemar, maka dapat diketahui pula daerah-daerah yang mungkin terkena pencemaran gas, sehingga akan mudah dalam penanganan lebih lanjut.

Dengan adanya aplikasi ini, maka industri-industri atau tempat-tempat pertambangan yang mempunyai kerentanan terhadap kebocoran pipa dapat melakukan simulasi-simulasi dengan parameter yang berubah-ubah dan disesuaikan dengan kondisi yang sebenarnya, maka industri tersebut dapat membuat petunjuk pelaksanaan yang lebih kongkrit dalam menanggulangi bencana akibat kebocoran pipa. Aplikasi ini juga dapat digunakan pada saat 
terjadinya kebocoran pipa. Dengan memperhatikan arah angin dan kestabilan atmosfer yang terjadi pada saat itu, maka pihak industri dapat dengan cepat melokalisir daerah pencemaran.

\section{KESIMPULAN}

Berdasarkan hasil pembuatan aplikasi ini dapat diambil kesimpulan sebagai berikut.

1. Sistem telah dapat bekerja dengan baik dan bersifat user friendly, terbukti dengan memasukkan angka-angka sembarang pada input yang tersedia dan menekan tombol pilihan medium anisotrop dan fluida diam sistem dapat memunculkan grafik dan angka yang diinginkan.

2. Sistem aplikasi ini dapat digunakan untuk menghitung sebaran konsentrasi gas baik untuk difusi fluida diam dan difusi anisotrop yang tampilannya berupa grafik 3-Dimensi maupun 2-Dimensi serta dalam bentuk tampilan angka.

3. Dengan aplikasi ini, industri atau pertambangan yang mempunyai kerentanan terhadap kebocoran gas dapat memanfaatkannya sebagai alat pemantauan lingkungan.

4. Aplikasi ini juga dapat digunakan sebagai alat Bantu ajar, baik untuk kalangan ilmu lingkungan maupun untuk kalangan ilmu teknik informatika.

\section{DAFTAR PUSTAKA}

1. CORNWELL, DAVIS, 2001, Introduction to Environtmental Engineering, McGraw Hill, New York.

2. IMARJOKO,Y.I, 1998, "Pemodelan dan Simulasi pada Analisis Lingkungan", Diktat pada Diklat Pemodelan dan Simulasi dalam Analisis Lingkungan, PATN-BATAN Yogyakarta.

3. PASQUILL, F. 1961, The Estimation of The Dispersion of WindBorne Material, Met.Mag., 90: 106, 33-49.

4. GIFFORD, F.A., 1961, Use of Routine Meteorological Observation for Estimating Atmospheric Dispersion, Nuclear Safety, 2, 47-51.

5. GIARRATANO, J., 1993 Expert Systems Principles and Programming, PWS Publising Company, Boston USA.

6. ARCADIO, P.S., and Gregoria, A.,S., 1996, Environmental Engineering : A design Approach, Prentice Hall Company, New Jersey USA. 